Meta

Journal des traducteurs

Translators' Journal

\title{
Project-Based Learning: A Case for Situated Translation
}

\section{Don Kiraly}

Volume 50, numéro 4, décembre 2005

Pour une traductologie proactive - Actes

For a Proactive Translatology — Proceedings

Por una traductología proactiva - Actas

URI : https://id.erudit.org/iderudit/012063ar

DOI : https://doi.org/10.7202/012063ar

Aller au sommaire du numéro

Éditeur(s)

Les Presses de l'Université de Montréal

ISSN

0026-0452 (imprimé)

1492-1421 (numérique)

Découvrir la revue

Citer cet article

Kiraly, D. (2005). Project-Based Learning: A Case for Situated Translation. Meta, 50(4), 1098-1111. https://doi.org/10.7202/012063ar

\section{Résumé de l'article}

Dans cet article, l'auteur propose de remplacer la théorie populaire, d'après laquelle le processus d'apprentissage est considéré comme un simple transfert d'informations, par une perspective cognitive multi-dimensionnelle. Un scénario basé sur des projets de traduction authentique est présenté pour illustrer des implications potentielles d'une telle approche. Ensuite, l'auteur propose d'observer des situations d'apprentissage collaboratifs dans le but de mieux comprendre les processus cognitifs impliqués dans la traduction et son apprentissage.
Ce document est protégé par la loi sur le droit d'auteur. L'utilisation des services d'Érudit (y compris la reproduction) est assujettie à sa politique d'utilisation que vous pouvez consulter en ligne.

https://apropos.erudit.org/fr/usagers/politique-dutilisation/ 


\title{
Project-Based Learning: A Case for Situated Translation
}

\author{
DON KIRALY \\ Johannes Gutenberg University Mainz, Mainz, Germany \\ don.kiraly@gmx.de
}

\begin{abstract}
RÉSUMÉ
Dans cet article, l'auteur propose de remplacer la théorie populaire, d'après laquelle le processus d'apprentissage est considéré comme un simple transfert d'informations, par une perspective cognitive multi-dimensionnelle. Un scénario basé sur des projets de traduction authentique est présenté pour illustrer des implications potentielles d'une telle approche. Ensuite, l'auteur propose d'observer des situations d'apprentissage collaboratifs dans le but de mieux comprendre les processus cognitifs impliqués dans la traduction et son apprentissage.
\end{abstract}

\begin{abstract}
The author proposes replacing the folk theoretical 'conduit' view of learning that still predominates in Translator Education with a principled understanding of cognitive and learning processes for the design of learning events in Translator Education. A collaborative, project-based educational experience is presented by way of illustration. In conclusion, an argument is made for studying collaborative learning events to gain insight into the multi-facetted nature of the learning process as well as of the translation process itself.
\end{abstract}

\section{MOTS-CLÉS/KEYWORDS}

translator educator, cognitive processes, project-based learning, translator training

\section{Introduction}

Well over half a century after the first university-level schools for translator training were established in Europe, Translator Education may be on the brink of leaving behind its wallflower existence on the periphery of Translation Studies and becoming not only a full-fledged domain of research, but also a professional pedagogical enterprise. The need to adapt educational practice to rapidly changing market needs has become acute; a plethora of pertinent methodological and theoretical resources and tools is available from related disciplines; and translation teachers and researchers are showing increasing interest in seeking alternatives to effete teaching methods - alternatives that will be better suited to the needs of students and employers against the backdrop of the radically changed market conditions over the past half century. The monograph by González Davies (2004), with its emphasis on an eclectic pedagogical framework and the need for a professional orientation in the educational setting, is a prime example of the emerging Zeitgeist in Translator Education.

Yet the inertia of the conventional trial-and-error approach to teaching is still a force to be reckoned with, grounded as it appears to be in a pervasive folk theory of learning. The performance magistrale, both a demonstration of the teacher's superior 
wisdom and an attempt to duplicate knowledge in students' minds, appears to be a holdover from the earliest days of Translator Education, when Translation Studies began to emerge as an appendage to the field of philology. It is a technique that has been passed down from generation to generation of translation teachers in the absence of concerted multi-disciplinary efforts to establish true pedagogies of translation reflecting what we know today about the dynamic complexity of language mediation. In this article, I present a case for setting aside persistent folk theoretical views of learning and pursuing inter-disciplinary inquiry to develop first-rate teaching approaches and techniques that will motivate learners and teachers alike. I suggest that research into the learning process can help to verify the efficacy of different teaching approaches and techniques, like those proposed by González Davies (2004) and in particular, project-based learning. Drawing on recent trends in cognitive science and learning theory, I will suggest that the observation of learning processes within the context of real translation projects carried out in a pedagogical setting will not only confirm the inestimable value of such projects for the development of translator competence, but they will also shed light on the cognitive and social aspects of the translation process itself.

\section{The Competence Gap in Translator Education}

As we all know, market research is a mainstay of modern business practice. If we want our products and services to be accepted by the market, we must conduct survey research among market participants. If we want to investigate the efficacy of the Translator Education programs we offer, one of our main sources of information will be the translation services market. While the results of global translation market research may not be readily available, two surveys of national translation markets do provide us with some food for thought. First, a survey of representatives of the Canadian translation industry on the threshold of the 21st century revealed a considerable gap between the needs of the translation services market and the level of professional translator competence acquired by students over the course of their studies:

Our surveys have also shown that employers have definite expectations of new graduates in translation, and they are finding that the universities fall short of meeting their expectations regarding required skills and preparation for being on the work force. The main obstacles encountered when hiring graduates are their narrow exposure to culture, lack of practical training and difficulty in working independently. Translation firms claim that university training is too theoretical. (Canadian Translation Industry Sectoral Commission, p. 19)

Similarly, in a survey carried out within the framework of the POSI project on Translator Training sponsored by the Féderation International des Traducteurs (FIT), Mauriello (1999) found that translation buyers and translator employers in Italy, while largely satisfied with recent graduates' language and translation skills, were dissatisfied with their preparation for dealing with specialized translation, terminology management and information technology, but also with their ability to organize themselves autonomously or work together in teams, solve problems or establish and effectively manage interpersonal relations on the job. Mauriello suggests that this phenomenon is likely to be pervasive in other countries as well. Assuming that this is 
indeed the case, the question naturally arises as to why our university-level programs seem unable to equip our students with the essential intellectual and interpersonal skills and capabilities they need upon graduation.

\section{WTNS: A technique with a past. But does it have a future?}

In referring to the findings of the survey of the Canadian translation industry mentioned above, Echeverri specified what he sees as one of the main causes behind the pedagogical gap in translator education:

La performance magistrale, approche pédagogique généralement privilégiée au Canada et ailleurs, ne favorise pas l'autonomie des futurs traducteurs... (Echeverri, 2004).

Similarly, in the introduction to their recent edited volume on innovation in translator education, Baer and Koby write:

[...] We may hope to better prepare students for the workplace by offering them appropriate tools, but if our teaching methodology is of the traditional kind - performance magistrale described by Jean-Rene Ladmiral (1977) in which the master passes on his/ her knowledge to a passive apprentice - we may fail to produce translators who are capable of the flexibility, teamwork and problem-solving that are essential for success in the contemporary language industry, not to mention the creativity and independent thinking that have always been the hallmark of the finest translators (2003:vii-viii).

I suggest that the performance magistrale, or as I will call it in this paper: the 'who'll take the next sentence' (WTNS) approach, is not so much the root of the problem as it is a symptom of the folk theoretical view of learning (and hence of teaching) that predominates in our field and that is perhaps the key obstacle to the development of a dynamic pedagogical culture in the domain of translator education. In fact, I will go a step further to suggest that this folk theoretical view may be largely responsible not only for the lack of autonomy of our graduates, but for the other deficiencies identified in the two surveys mentioned above as well. What I will be dealing with throughout the remainder of this article is what might happen if we were to begin to draw on contemporary findings in the field of cognitive science to inform Translator Education.

It is worthy of note that the unequivocal criticisms of the 'performance magistrale' quoted above came two decades after I began work on my dissertation in the area of translation teaching, which was eventually published under the title Pathways to Translation (1995). In that work, I outlined the state-of-the-art of translation teaching at the time, carried out a first-generation think-aloud-protocol study on novice and graduate translators, and proposed an exploratory approach for the development of learning-centered methods for translator education. The project had emerged essentially as an action research project from my personal struggle to come to grips with nothing other than the 'performance magistrale'. In my depiction of this conventional technique, the teacher attempts to 'train' translators by having them practice translating on their own at home and then correcting their homework one sentence at a time.

In this scenario, the in-class instructional process is largely reduced to homework review - where the instructor essentially identifies the errors in students' drafts and provides 'correct' solutions to translation problems. Here, given the very nature of the 
classroom setting, learning is seen as an incremental and potentially disembodied and desituated process. The teacher is supposed to possess knowledge of how to translate, which can essentially be transmitted to the students' minds for storage, recall and later transfer to other translation tasks. Rather than maintaining the natural complexity of professional translational activity as a social, inter-cultural and interpretive process, the specific function of the classroom is to decontextualize and disembody the learning process, and for the teacher to distribute knowledge in increments, which are supposed to combine to yield some sort of 'translator competence' in each individual student's mind.

\section{The Translator's Competence: It Depends on How You Look at It}

Translator competence has been a major focus of attention in Translation Studies for several decades now, with particular emphasis being placed on understanding translator competence in cognitive terms. In recent years, a schism has begun to emerge within the study of translation as a cognitive processes. The mainstream approach appears to be based on a first-generation 'information processing' view of the mind, but the most recent cognitive science approach, perhaps best exemplified in Translation Studies by the work of Hanna Risku, is moving along the lines of the more recent 'situated cognition' perspective, which takes a dynamic, situationally embedded view of mental processing, focusing on social, physical and emotional phenomena that extend far beyond the macro- and micro-strategies of the individual mind. (Risku 2002).

The information processing model of mental processes (under the premises of which I was also working while doing my own TAP study in the 1980s) sees the human mind as individual, brain-based, and 'complicated' much as a machine, a computer or other man-made artifact is complicated - predictable, programmable and essentially a sum of its parts. From this perspective, the learning mind accumulates increments of knowledge and skills in a linear, sequential, predictable and pre-definable manner.

Yet one of the current focal points within cognitive science is the acknowledged distributed nature of knowledge and cognition. Rather than seeing cognition as occurring solely within the brains and minds of individuals, it can also be seen as a function of interaction - in fact of co-emergence - of individuals with the social and physical environments in which we are integrated. This brings us to the crux of the present article: it can be hypothesized that 1) translator competence emerges as the result of the collaborative completion of authentic translation work, and 2) by observing translators, both non-professional and professional, in the socially-situated praxis of authentic translation work, we can acquire a privileged view of the nature of the translation process and glean readily applicable insights into how to best help students develop their capability to function as professional translators in the real world outside of the academic ivory tower.

As is surely the case in most highly complex cognitive endeavors-particularly where interpretation and social factors play a key role-the constellation of factors impinging on the intuitions and strategies at the translator's disposal is unique for each new translation task that a translator undertakes. There is a consensus in much of contemporary translation theory that translation is not primarily a recoding process where fixed strategies are memorized and applied in some clearly determinable 
sequence. Similarly, extensive research in the fields of expertise studies and cognitive science has demonstrated that cognitive strategies in ill-structured domains are largely heuristic and dynamic in nature and both personally and socially constructed - suggesting that translation strategies are constantly changing and evolving to serve the cognitive and social goals of the translator in the face of each new constellation and weighting of innumerable factors.

Translation can hence be seen as 'situated' cognitive activity; that is, it is always undertaken within a particular physical and social setting and interactional framework, with the translator working together with other actors, and with cultural, technical, documentary and linguistic tools and resources to design and create a text, that is, to 'textualize' a new situation (Risku, ibid). The translator's focus of attention moves away from anything resembling the mere transcoding of texts to the ways and means of interpreting and managing entire communicative situations. The production of situationally appropriate artifacts calls for much more than plugging in 'equivalent' linguistic elements or the off-the-shelf application of ready-made translation strategies. In the pervasive WTNS approach, each translated sentence will be proposed by a different student, thereby ignoring supra-sentential cohesion and coherence. In addition, the spontaneity and challenge of real-life reflection-in-practice are absent from this scholastic setting. Such an approach surely suggests to learners that the chunk-replacement process is at the heart of professional translation activity as well. If we begin to see the translation process itself as a creative situation- and experience-bound construction process, then translation skills instruction will also have to reflect this perspective.

\section{Authenticity in the Service of Autonomy and Expertise}

On the basis of a social constructivist view of learning, I have proposed an 'empowerment' approach to translator education revolving around 'authentic project-work'. By the latter I mean the collaborative undertaking of complete translation projects for real clients. The specific goal of this approach is to help students achieve a semiprofessional level of autonomy and expertise through authentic experience. From the perspective of ecological validity, the benefits of authentic work in translator education and professional assessment procedures are readily apparent. First of all, it seems plausible that having students handle real translation assignments embedded in authentic situations with the same sorts of complexity and problem-solving constraints that they can expect to face after graduation will be more motivating than having them complete mere exercises: translating teacher-selected texts with no real readership or client in mind, to be assessed by the instructor on the basis of scholastic (that is non-professional), and often arbitrary, criteria. We can hypothesize that students' self-confidence will improve if they can see progress in their work on the basis of what are demonstrably professional criteria. And we can also expect them to be better prepared for the market if they work on texts chosen to reflect the work actually done on the market rather than texts selected for the sake of expediency - like newspaper texts, which surveys have shown to be rare on the market, while representing the all-but-exclusive practice material in classes where the WTNS technique predominates.

In my study on the application of social constructivism to Translator Education (Kiraly, 2000), I demonstrated that a migration from classroom activities as exercises 
to pieces of work would entail radical changes in students' relationships to their instructors, their fellow students, and the professional community, as well as in their understanding of the learning and teaching process and their own self-concept as developing professionals. The changeover would entail a major shift in focus from static equivalence to a myriad of real-world factors including time pressure, professional responsibility, and self-assessment that would add real-world dimensions to otherwise lifeless exercises. Of course, second-guessing each teacher's idiosyncratic expectations can be a valuable experience as well, in the sense that after graduation, students can expect to work for various clients with their own idiosyncratic expectations and quality criteria. But the artificial nature of the learning-as-transmission classroom epistemology can hardly provide an adequate substitute for real-world work. Simulated practice may be useful for some kinds of learning - but only real praxis inside and outside the classroom can bring a complex profession alive.

As translation teaching practice has stagnated at a transmissionist1 level, translation theory has progressed and evolved with the changes in the language mediation professions themselves, coming to portray translation as a highly complex and illstructured social, cognitive, and cultural process. There are few if any 'rules' for translators to follow; there are no commonly accepted inventories of techniques, strategies or procedures that need to be acquired through classroom exercises and implemented in clearly categorized problem situations; there are no translation methods which, if carefully learned and applied, will lead the translator to the 'right' solutions. Translation is the epitome of an ill-structured domain - the translator's socially mediated yet personal history of experience serves as the interface for a succession of unique occurrences of inter-cultural communication.

\section{Implications for Teaching}

Hanna Risku's depiction of the translation student's role as that of an emerging text-design expert suggests that radically situated methods are needed for translator education:

Translations are, by definition, written for new situations, purposes, recipients and cultures. When you learn to translate, you have to learn how to gain an overview of a new situation with all its different cultural factors and, perhaps, even more importantly, you have to learn how to position yourself in this communication system and define your own situational role, goal and tasks. (ibid: 526)

While Risku does not go so far as to propose an actual teaching methodology or any specific didactic techniques for translator education, the general recommendations she makes clearly point in the direction of authentic, situated pieces of work. She suggests that curricula be based on specialized areas of professional translation as well as more general activities including research, situation analysis, design text formulation and teamwork. But she points out that these skills must be applied within relevant contexts if they are to be viable. As she says:

$[\ldots]$ it is paramount that teachers of translation and interpreting integrate authentic or near-authentic translation tasks into their teaching. (ibid: 530-531)

In her view, an authentic learning situation can be achieved by having students manage the entire range of tasks involved in the translation process, from terminology 
and information management to project management and teamwork. As she points out, cognitive and social skills are closely related. In her words, "by assuming the role of the expert, we develop the ability to cope with the challenges imposed by that role. Thus universities could offer situations in which we exercise social roles" (ibid: 531).

Risku goes well beyond the specific findings of the research on which she reports to hypothesize important benefits of authentic translation work in the classroom:

Along with autonomy, responsibility and emotional involvement, motivation increases as well as the willingness to initiate action oneself instead of simply completing assignments. (Risku 1998: 114)

In the same vein, the goal of my social constructivist approach is precisely to 'empower' students by making them proactive agents of their own learning through authentic, collaborative work leading to autonomy and expertise.

\section{A multi-dimensional view of learning}

The adoption of a collaborative learning environment need not involve a polarizing, uni-dimensional view of the learning process. In fact, it can be hypothesized that if we can establish a coherent relationship between these views of learning, we can move beyond both default WTNS translation teaching practice and at the same time promote the development of a variety of teaching approaches adapted to the specific constraints of the many different contexts in which translators learn. For example, recent work by Tara Fenwick (in press) in the field of educational policy studies, shows how different modes of learning (and consequently of teaching) can all be valid ways to approach certain learning tasks. Fenwick specifically refers to four models of learning theory that have been applied in studying adult education: acquisition, reflection, practice-based community process, and embodied co-emergence.

\subsection{Learning as acquisition}

Acquisition refers to information processing in the individual's mind. It is not only knowledge that is acquired, but also strategies and capacities for developing new knowledge and coping with unfamiliar situations. The focus is on the individual's conscious rational mental processes (like perception, interpretation, categorization and knowledge storage). Schema theory, which is well represented in Translation Studies, for example in the context of TAP research, suggests that we first acquire new information, interpret it according to our previous experiences, then evaluate and remember concepts using our existing mental schemata or categories, and restructure our concepts and organizing schemata as we are challenged by new experiences.

\subsection{Learning as a socio-cognitive reflective process}

From this perspective, the individual is the primary actor in a process of theorizing and personal meaning making. As learners reflect on their experiences, they actively interpret what they see and hear, and thereby construct and transform their own unique knowledge. Fenwick views both the radical constructivism of Piaget and von Glasersfeld as well as Vygotsky's social-constructivism as reflecting this type of learn- 
ing. The field of expertise studies [exemplified by the work of Schön (1987) and Bereiter \& Scardamaglia (1993)] has emphasized the reflective aspect of the learning process. Pym speaks in terms of personal theorizing on the part of learners:

The minimalist approach basically sees translating as a process of producing and selecting between hypotheses, and this is in itself a mode of constant theorization. If thought through, the model is actually claiming that translators are theorizing whenever they translate; theorization is an important part of translation practice (Pym 1993: 491)

Similarly, Kaiser-Cooke (2003) argues that theorizing is an essential part of all intentional action in the world including translation practice. For her, becoming a translator necessarily entails both learning from theory and learning through practice.

\subsection{Learning as a practice-based community process}

Learning can also be seen to be rooted in the (socio-cultural) situation in which a person participates, rather than in the head of that person as intellectual concepts produced by reflection. Exemplified by Bruffee (1995), this approach sees the learning process as entailing the joining of communities of practice. Starting out as outsiders, novices gradually acquaint themselves with the practices and ways of thinking of these communities by being involved in their professional activities, first at the periphery and then gradually moving into full participation. From this viewpoint, learning essentially involve interrelations between the learner and other people. As in the social-constructivist perspective, language from this viewpoint is a socially grounded tool of cultural mediation.

\subsection{Learning as a co-emergence}

This view of learning, based on recent developments in cognitive science, explores how cognition, identities and environment co-emerge simultaneously through learning. From this viewpoint, the systems represented by the individual and his context are inseparable, and cognition occurs in the interplay of mutually emerging systems affected by the interplay of one with the other. From this viewpoint, people are themselves comprised of biological, psychological and neurological systems and are intricately interconnected with the social and physical systems in which they act. This is the most all-encompassing view of learning that Fenwick proposes, a view that subsumes the others that she presents.

If we take a multi-facetted perspective of learning processes, we need not throw out the didactic baby with the bathwater, but can instead see effective teaching as addressing different aspects of learning, depending on whether the learner is focusing on the learning of facts, the construction of personal or social meanings or becoming part of communities of practice. I suggest, however, that the co-emergence level can provide an over-arching holistic and humanistic backdrop that can help us effectively frame learning experiences as depicted in the figure below: 
FIGURE 1

A Multi-Facetted View of Learning Processes

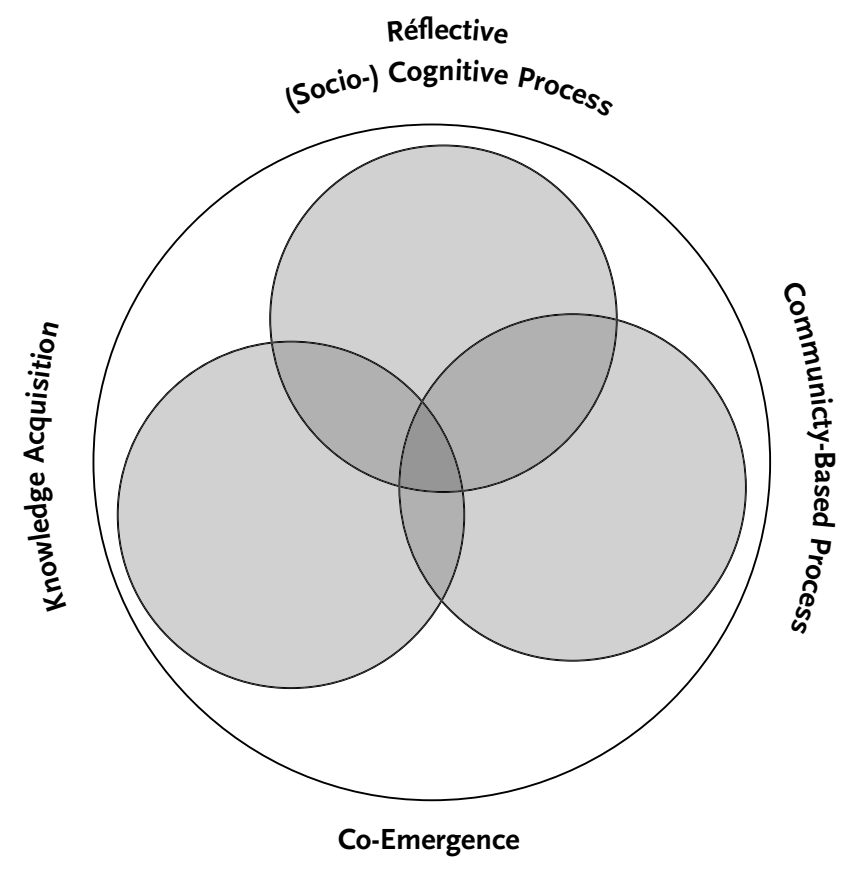

\section{A Subtitling Project: Situated Translation in the Classroom}

A project completed in the winter semester of 2004/05 with a class of advanced translation students illustrates the potential of the authentic project as the focus of learning as a co-emergent process. The project began with a request for assistance from a colleague who teaches subtitling at my home institution. She had been requested by a small German film production company to subtitle a documentary with her students into English. As all teachers at our institution work only into their native language, this colleague asked if I would be interested in taking on the work as a class project. Although I had personally had no experience with subtitling myself, the students to whom I presented the project were keen to tackle it. The tasks that emerged for me as the 'teacher' over the course of this project were complementary but not hierarchically superior to those of the students. The students and I agreed to enlist the aid of a tutor who was familiar with the basics of subtitling and who could teach us the mechanics of Subtitle Workshop ${ }^{\circledR}$, a freeware program for semi-professional subtitling work.2 We arranged to have two 90-minute workshop sessions in which we would learn the basics of subtitling with the help of the tutor. We would then divide up the film tracks and have each pair of students (in a class of 14) prepare part of the subtitles, which would then be peer-reviewed and finally subjected to full-group review. We had agreed with the client that we would complete the subtitles in 16 weeks and that we would forward them to the company electronically in a mutually agreedupon format. We were given a specific font type and size to use and were informed that the company required the subtitles to have a maximum length of 32 characters. 
The first stage of the project would to involve the acquisition of basic principles and norms of subtitling and the technical knowledge needed to handle our chosen subtitling program. During the course of the two introductory workshop sessions, our tutor pointed out the often conflicting constraints on the subtitler, for example where the constraint of keeping sense units together on screen conflicted with the maximum allowable number of characters in a subtitle. Even during this initial workshop phase, social constructivist learning was readily apparent as we created our common understandings of the mechanics and conventions of good subtitling. We eagerly worked with the information presented by the tutor, but we were constantly engaged in an interactive process of developing heuristics for ourselves that we could actually use to begin our translation work.

Personal reflective work clearly proceeded in parallel to our group work, with each individual student gradually developing a feel for the often contradictory constraints involved in creating subtitles. This was clearly apparent as individual students began subtitling segments of the film on their own at home and then comparing them with their group members in class. Discussions were lively and insightful as this phase of the work got under way. Our tutor continued to attend our classes for three weeks to provide assistance, but the students had already largely moved on to a rather autonomous stage of social and personal knowledge construction, and they clearly preferred resolving problems within their small groups rather deferring to the tutor. As the sole native speaker informant in the class, I moved from group to group and provided assistance resolving difficulties involving vocabulary choice, idiomatic usage, stylistic infelicities and the like, and I also provided my constructive criticism as a translator and fellow novice subtitler. But the vast bulk of the actual subtitling work from research to the rough drafts through the two revision stages and our final corrections was done by the students in changing constellations. 'Teaching' in a conventional sense was limited essentially to the two introductory sessions with our tutor, while the remainder of the class evolved into a self-regulating workshop, with each session's activities being guided by the needs and will of the group on the respective day.

It would be a fair depiction to say that the project developed a life of its own. It became the group's raison d'être; the need for the teacher-centered transmission of knowledge and sticking to a lesson plan evaporated against the backdrop of our realworld responsibilities: acquiring, creating and applying the knowledge needed to complete our project in a timely and competent manner.

Halfway through the course, the opportunity presented itself for a professional subtitler to attend our class and critique our work. As we had already developed crude subtitling skills on the basis of our initial instruction and our joint knowledge construction over a five-week period, our visitor was able to point out discrepancies between our understandings of how to subtitle and her day-to-day experience in the domain. That 90-minute session was of tremendous importance to each of us individually and to the group as a whole. As the features of our subtitles were for the most part in line with acceptable professional practice, the lively interaction in the group on that day revealed that both we and our visiting professional saw the class as an emerging, semi-professional subtitling team. Instead of giving us conventional pedagogical feedback in terms of right or wrong, she intuitively gave us numerous suggestions that we were then able to draw upon in revising our first batch of subtitles and 
moving on to the second half of the film. Contributions by most of the students during that session reflected the sense of self-confidence that the students were developing as well as their awareness of and ability to resolve problems as they were pointed out to them.

As we approached the end of the semester, we submitted a sample batch of our subtitles and were promptly informed by our clients that they were unable to import them into their Macintosh ${ }^{\circledR}$-based system. They also informed us that they actually needed the subtitles to be of no more than 26 characters in length, rather than the 32 originally agreed upon. This meant we had to go back and revise all 250 of the subtitles we had already completed, and condense the gist of each one even more. Rather than seeing this as a major problem, the students took it as a challenge and in fact learned a great deal by being forced to refashion each subtitle without losing its essence. When I mentioned the importing problem to the group, students suggested that they could travel to the company (130 kilometers away) in pairs to enter the subtitle by hand into the company's program. Ten students immediately volunteered and we arranged with the company to have each pair spend one full day learning how to use the company's software and hardware and actually entering one fifth of the subtitles. As it turned out, the owner of the company, who assumed responsibility for introducing the students to the company's software and hardware, had no significant practical knowledge of subtitling himself. In addition, the software to be used for subtitling the film on site was actually film-cutting software with an extra (and very complicated) subtitling feature that was radically different from the PC-based subtitling solution we had become familiar with.

It was at this point that the co-emergent nature of our learning enterprise became particularly apparent. As it turned out, it was the students who wound up teaching the filmmaker how to create subtitles with his own hardware and software. In hindsight, this feature was symptomatic of the entire course. Rather than being essentially characterized by the simple transmission of knowledge from a more knowledgeable 'teacher' to less knowledgeable 'learners', the project became a multi-directional and multi-facetted process of knowledge acquisition, individual and social knowledge creation, and the development of a learning community that functioned as a microcosm of real-world subtitling practice. The quality of the final subtitles was clear evidence of the competence we had developed as a team, and the company's overwhelming praise of the students' ability to tackle and complete their difficult new task demonstrates the tremendous degree of autonomy attained by each pair of students over the course of this one project.

This is but one example of a series of authentic translation projects completed in a similar way over the course of the past ten years. Always starting from and winding up with an authentic translation task, learning has been seen as co-emergent with the product, both at the group and individual levels, and for the teacher and students alike. Our translation projects have included several chapters of a coffee-table book on a region in Germany, 200 pages of online program descriptions for the University, a number of smaller websites brought in by students, a 100-page website on Cuba, an academic monograph on psychoanalysis and witchcraft (which was later published in the UK), the image brochure for our home university, and another current project involving the translation of descriptive texts on the work of a series of non-profit organizations involved in international and intercultural education. 
The very nature of such project work, involving relatively large volumes of text to be translated under considerable time pressure, precludes the use of the default WTNS approach. The real-world exigencies of time constraints and the unique set of problems that emerge in each project require the group to work together as a team with the teacher's assistance. These very constraints promote a view of learning essentially as a personal as well as social construction process. Transmission certainly plays a role, but it has tended to be a minor one. The market requires that the final product be of impeccable quality and that it conform to the translation norms on the market. Competence and autonomy are necessary by-products of such a learning process.

Over the course of a given project, the students must find and/or develop and use the cognitive, human, and documentary resources necessary to produce a professional quality job on time. The ways and means of accomplishing these goals vary greatly from group to group, from project to project and from student to student. In the individual tests required by the university at the end of each semester, my main criterion for summative assessment always boils down to "how long does it take me to take the student's work and turn it into a professional quality product ready to be submitted to a client?" Having completed projects under real-world conditions, the students can almost universally relate very well to this criterion and they tend to perform at a very high level of proficiency and to adapt quickly and willingly to a constructive approach to learning. This the is heart of the empowerment approach: by providing students with opportunities to work authentically on the real-world translation market, by encouraging them to construct personally viable meanings and skills in collaboration with peers and outside professionals, and by explicitly serving as their assistants, guides and facilitators in this highly individualized process, we can empower our students as autonomous semi-professionals, ready to move out onto the market upon graduation and assume the expert roles that will be expected of them.

Here, co-emergence - the cognitively situated interplay of the learner with the social, physical and cultural environment, whereby both the environment and the learner undergo constructive change - plays a key role. From this perspective, the (lifelong) translation student is in a perpetual process of embodying the practice of the professional translator. Within this overriding perspective, corresponding perhaps best to the emergence of translator competence through a series of authentic experiences of translation practice, we can also see the student as theorizing, proposing and testing hypotheses at many different levels, both individually and collaboratively with peers, professional translators, clients and special subject specialists. At the same time, we can see the learner as being involved in the process of joining professional communities, including that of professional translators, computer users for language mediation purposes, terminologists and project coordinators. Knowledge transmission and acquisition may best reflect lower-level learning and the initial contact to macro- and micro-strategies, which can be expected to change through dynamically authentic experience.

\section{Conclusion}

A potentially viable approach for investigating the genesis of translator competence would be to focus on the observation of interaction and learning in situated translation 
projects within educational settings. Qualitative case studies of translation in situation can contribute significantly to the triangulation of claims concerning the enactive nature of cognition and learning like those introduced in this chapter. Highly authentic and naturally complex translation situations would allow us to observe the interplay of authenticity, emerging autonomy and developing competence both within groups and individuals. In fact, it is plausible that investigating the genesis of translator competence can lead us to a deeper understanding of the nature of that very competence. It may also help us to break the stranglehold of the "who'll take the next sentence" teaching technique on translator education.

\section{NOTES}

1. There are of course notable exceptions, like González Davies (2004), mentioned above. She presents a wealth of pedagogical activities for translator education from guided exercises to authentic projects. One particularly valuable feature of her work is her eclectic view of learning processes. Rather than restricting her perspective to social constructivism, for example, she demonstrates how learning processes can be seen as multi-facetted, thereby bridging the ideological gap teachers might see in discourses pitting, for example, constructivism against objectivism.

2. Richard Samson's collaborative approach to the use of this program, as demonstrated in our joint summer courses for translator educators held in Vic in 2004, served as a key source of inspiration for the project reported on here (http://www.uvic.es/fchtd/especial/en/collaborative_translation_ teaching.html).

\section{REFERENCES}

Baer, B. J. and G. S. Koвy (2003): “Introduction: Translation Pedagogy: The Other Theory,” in BAer, B. J. and G. S. Кову (eds.) Beyond the Ivory Tower, Amsterdam/Philadelphia, John Benjamins, p. i-viii.

Bruffee, K.A. (1995): Collaborative Learning, Baltimore, John Hopkins University Press.

Bereiter, C. and M. Scardamalia (1993): Surpassing Ourselves, Peru, Illinois, Open Court.

Canadian Translation Industry Sectoral Commission (1999): "Survey of the Canadian Translation Industry."

Dewey, J. (1938): Experience and Education, New York, Simon \& Schuster.

ECHeVerRI, Á. (2004): "Stratégies d'apprentissage versus performance magistrale dans les cours de traduction," unpublished presentation given at the ACFAS Conference, Montréal.

Gallimore, R. and R. Tharp (1990): Teaching Mind in Society: Teaching, Schooling and Literate Discourse in Moll, L.C. (ed.) Vygotsky and Education. Instructional Implications and Applications of Sociohistorial Psychology, Cambridge, CUP.

Fenwick, T. (In press): Rethinking Processes of Adult Learning, in Foley, G. (ed.) Understanding Adult Education and Training (3rd edition), Sydney, AU, Allen and Unwin.

GonzÁlez Davies, Maria (2004). Multiple Voices in the Translation Classroom, Amsterdam, John Benjamins.

Kaiser-Cooke, M. (2002): "How do They do it? The Nature of Translational Expertise," Across Languages and Cultures 3-1, p. 59-70.

Kaiser-Cooke, M. (2003): Translation, Evolution und Cyberspace, Frankfurt am Main, Peter Lang.

Kiraly, D. (1995): Pathways to Translation, Kent, Ohio, Kent State University Press.

Kiraly, D. (2000): A Social Constructivist Approach to Translator Education, Manchester, St. Jerome.

Mauriello, G. (1999): «Training Translators to Face the Challenges of the Future», in Actes $d u$ $X V^{e}$ Congrès Mondial de la Fédération Internationale des Traducteurs (FIT), p. 170-175.

Nord, C. (1994): „Aus Fehlern Lernen: Überlegungen zur Beurteilung von Übersetzungsleistungen“, in Snell-Hornby, M., Pöchhacker, F. and Kaindl, K. (eds.). Translation Studies: An Interdiscipline. Amsterdam: John Benjamins, p. 363-376. 
Nord, C. (1996): „Wer nimmt denn mal den ersten Satz? Überlegungen zu neuen Arbeitsformen im Übersetzungsunterricht, “ in Lauer, A., Gerzymisch-Arbogast, H., Haller, J. and STEINER, E. (eds.) Übersetzungswissenschaft im Umbruch, Tübingen, Gunter Narr, p. 313328.

Pacte Group (2003): “Building a Translation Competence Model," in Alves, F. (ed.) Triangulating Translation, Amsterdam, John Benjamins, p. 43-66.

Pyм, A. (2003): "Redefining Translation Competence in an Electronic Age. In Defence of a Minimalist Approach," Meta 48-4, p. 481-497.

Risku, H. (1998): Translatorische Kompetenz. Stuttgart, Stauffenburg Verlag.

Risku, H. (2002): "Situatedness in Translation Studies," Cognitive Systems Research 3, p. 523533.

Sснмітт, P.A. (1997): Evaluierung von Fachübersetzungen in Wotjak, G. and H. Sснмidt (eds.) Modelle der Translation/Models of Translation, Frankfurt am Main, Vervuert Verlag, p. 301332.

SснӧN, D. (1987): Educating the Reflective Practitioner, San Francisco, Jossey-Bass.

Vygotsky, L. S. (1994): "Extracts from Thought and Language and Mind in Society," in STIERer, B. and J. MAYвin (eds.) Language, Literacy and Learning in Educational Practice, Clevedon, Multilingual Matters, p. 45-58. 